\title{
Multiscale Reinforcing Interlayers of Self-same P(St-co- GMA) Nanofibers Loaded with MCF for Polymer Composites and Nanocomposites
}

Farzin Asghari Arpatappeh ${ }^{1}$, Berk Emre Aydemir ${ }^{1}$ Kaan Bilge $^{1}$, Melih Papila ${ }^{1 *}$

${ }^{1}$ Materials Science and Nano-engineering Program, Faculty of Engineering and Natural Sciences, Sabanci University, 34956 Tuzla, Istanbul, Turkey.

\begin{abstract}
Electrospinning has become a proven technique to introduce polymeric sub-phases into composites. The sub-phases such as nanofibers can also be used as a carrier platform for reinforcing particles at different scales, enabling a multiscale reinforcement approach. However, the polymeric nanofibers may lose their intended fibrous morphology during the composite curing at elevated temperature. As such, polymeric sub-phase can not contribute effectively as fibers to the mechanical properties of the composite. This paper exemplifies introduction of milled carbon fibers (MCF) carried by electrospun polymeric nanofibers and the use of the resultant multi-scale reinforcement as interlayer within conventional structural composites. The issue of polymeric nanofibers exposed to elevated temperature curing is circumvented by implementing a novel self-same nanofibrous strategy. While a base polymer for the nanofibers is chosen as epoxy compatible $\mathrm{P}(\mathrm{St}-\mathrm{co}$-GMA), its derivative by a cross-linker Phthalic Anhydrate, $\mathrm{P}(\mathrm{St}-\mathrm{co}$-GMA)/PA is also incorporated by dual-electrospining, i.e. simultaneous electrospinning of the two polymers. It was shown that the nanofibers of the base polymer melt and fuse over the cross-linkable nanofibers forming the self-same nanofibrous morphology during the heat treatment in accordance with the cure cycle of the epoxy resin in this study. MCFs were mixed into the cross-linkable polymer solution and electrospun with the P(St-coGMA)/PA nanofibers. The dual polymer and MCF loaded nanofibrous structures were analyzed morphologically before and after heat treatment. Homogenous distribution of particles in the fibrous structures, melting of the neat copolymer, crosslinking of the polymer mix, and selfsame fibrous structure were characterized. The nanofiber mats were used as the reinforcement to epoxy resin films and as interlayers for carbon fiber-reinforced composites. In the case of nanocomposites, MCF enhanced the elastic modulus by about $9 \%$. In the use of multiscale nanofibrous mats as interlayers of continuous carbon fiber composites, they improved the ultimate tensile strength of a cross-ply laminate by $9 \%$.
\end{abstract}

Keywords: Multiscale interlayer, Selfsame reinforcement, Matrix-compatible polymers, Milled Carbon Fiber (MCF), Electrospinning, Mechanical properties, composites, nanocomposites, fiberreinforced composites 


\section{Introduction}

Potential contribution of mechanically strong particulates into composites may be suppressed by inhomogeneous dispersion, agglomeration and poor particle/matrix interface area [1-3]. Methods associated with the particle dispersion, chemical compatibility/functionalization of the particle surface and polymer matrix have been thoroughly investigated. In contrast to direct mixing/blending into the matrix, homogeneity of the reinforcing particles can be effectively achieved by the use of polymeric nanofibers as their carrier. As for the chemical compatibility, the modification of common polymers with matrix-compatible functional groups has been used. For example, if epoxy is aimed to be used as the matrix, proper monomers can be used which contain breakable chemical groups such as epoxy rings. The epoxy rings on the polymer chain are broken by heat as those on the chains of epoxy matrix. Then, the hardener binds these dangling groups together - to result in crosslinking. It has been reported $[5,6]$ that the bond strength in the nanofiber/matrix interface was improved for an epoxy resin through the modification of polystyrene with an epoxy -compatible monomer - glycidyl methacrylate (GMA). The copolymer reinforcement, P(St-co-GMA), folded the modulus of the composite 10 times in three-point bending, when compared to that of polystyrene [7]. Presence of GMA in the nanofibers of $\mathrm{P}(\mathrm{St}-\mathrm{co}-\mathrm{GMA})$ resulted in a $18 \%$ improvement in the tensile strength of carbon fiber/epoxy composites $[8,9]$.

Another research [10] reports an improvement applied to P(St-co-GMA) nanofibers for their use beyond the glass transition temperature, Tg. Two classes of nanofibers were produced: one containing the base polymer and the other a mix of the polymer with phthalic anhydride (PA) - a crosslinking agent. The stabilization of the base polymer P(St-co-GMA) at elevated temperature was found to increase by increasing the ratio of PA in the mix. When the combination of these two nanofibers was heat-treated, the nanofibers from the base polymer melted while the nanofibers from the mix of polymer and PA crosslinked. Furthermore, the molten polymer was fused over the crosslinked fibers - leading to a self-same morphology.

Carbon-based reinforcements are the most preferred reinforcing agents for polymeric composites both in the form of fibers and in the form of particles. Milled carbon fibers (MCF) are among them to reinforce polymer resins. The contribution by these particles is typically suppressed because of poor interfacial compatibility and dispersion. In this research, dispersion of MCF particles is expected to be improved by using the electrospinning technique. This way, MCF particles are planned to be homogenously transformed to a reinforcing interlayer for composites.

\section{Experimental}

$\mathrm{P}$ (St-co-GMA) were prepared in accordance with another work of this research group [7]. The polymer composition was analyzed by FT-IR, Thermo Fischer Scientific Nicolet IS10. The thermal properties of the polymer were investigated by thermogravimetric analysis (TG) (Shimadzu DTG$60 \mathrm{H}$ ) and dynamic scanning calorimetry (DSC) (TA Q2000). Failure surface images were obtained using FE-SEM, Zeiss, Leo Supra VP 35.

Two classes of polymer solutions were prepared in dimethylformamide (DMF): P1. in-house synthesized base polymer Pst-co-GMA (30 wt.\%) and P2. the base polymer (20 wt.\%) along with a crosslinking agent named phthalic anhydride (PA) and an initiator named tributylamine (TBA) [10]. In addition to the polymer solutions, milled carbon fibers (MCF) from EasyComposites (MFG100) were added to the second mix to form suspensions (P2S) for electrospinning of MCF-loaded nanofibers. All solutions and suspensions were stirred overnight to secure their homogeneity.

The solutions and suspension were electrospun using the same production parameter setting: in $\sim 0.4$ $\mathrm{mL} / \mathrm{h}$ feeding rate, $12 \mathrm{kV}$ applied potential, and $10 \mathrm{~cm}$ tip-to-collector distance. Each solution/suspension was fed by a syringe pump (NewEra NE-100) through a needle with an inner diameter of $300 \mu \mathrm{m}$ while the electrostatic field was created by a high-voltage bias potential (Gamma 
High Voltage ES 30P-20W) in between the needle and an aluminum collector. Note that aside from espinning of the individual solutions and suspension (P1, P2 and P2S), dual-electrospinning (simultaneous use of two different polymer solution syringes) was performed to obtain two different nanofibers on the same mat. The two dual-fiber mats were by P1\&P2 and P1\&P2S.

The electrospun nanofibers were analyzed morphologically first using visual light microscopy (Nikon SMZ 1500 and Nikon Eclipse ME600). Then, after sputter-coating by Au/Pd (Cressington 108), they were analyzed in a scanning electron microscope (FE-SEM, Zeiss, Leo Supra VP 35). In order to reveal the effect of exposure to elevated temperatures as in composite curing cycles, the nanofibers were heated at $10^{\circ} \mathrm{C} / \mathrm{min}$ from room temperature up to $250^{\circ} \mathrm{C}$ and kept there for 1 hour in a box oven (Protherm PLF 130/6). Then, the samples were taken out of the oven and left to cool down to the room temperature. The heat-treated specimens were also analyzed morphologically as mentioned above.

Dual-electrospun polymer and polymer-particle solutions forming a single nanofiber mat was described as the self-same nanofiber layer (due to use of the same base polymer in all nanofiber types). Electrospun self-same layers were implemented in two ways: first as the nano-reinforcement of epoxy film forming nanocomposites and secondly as the interlayers of Carbon Fiber-Reinforced Composites (CFRC).

The nanocomposites were prepared from two layers of electrospun mats $(10 \mathrm{~cm} \times 10 \mathrm{~cm})$ which were subsequently infused by three layers of epoxy resin films (CMP-CP004).

Carbon fiber reinforced composites were chosen as cross-ply laminates, [0/90] stacking of four sheets of $30 \mathrm{~cm} \times 30 \mathrm{~cm}$ prepreg (CM-Preg T-C- 150/600 CP004). In the case of reference or neat CFRC, the UD prepreg plies were cut and used as is. However, in the case of nanofiber-interlayered CFRC, precut $30 \mathrm{~cm} \times 30 \mathrm{~cm}$ prepreg plies were first mounted on a metallic collector of the same size, and the polymer solutions were electrospun directly onto the prepreg surfaces. After covering the three such prepreg layers by electrospun nanofibers, the layers were stacked forming [0/I/90/I/90/I/0] where I stands for the nanofibrous interlayer. The laminates were vacuum bagged while laid between two caul plates and cured.

The cure cycle used for both nanocomposites and CFRCs was as follows: 1 . Heating from $30^{\circ} \mathrm{C}$ by $2^{\circ} \mathrm{C} / \mathrm{min}$ up to $90^{\circ} \mathrm{C}, 2$. Isothermal holding at $90^{\circ} \mathrm{C}$ for $1 \mathrm{~h}, 3$. Heating from $90^{\circ} \mathrm{C}$ by $2^{\circ} \mathrm{C} / \mathrm{min}$, up to $145^{\circ} \mathrm{C}$, the curing temperature of carbon prepreg, 4 . Isothermal heating in $145^{\circ} \mathrm{C}$ for $2 \mathrm{~h}, 5$. Cooling down to $30^{\circ} \mathrm{C}$. The nanocomposites processed in a hot press under 5bar, and the CFRC's were processed in a box oven under vacuum bag pressure only.

It is important to note the isothermal step (step 2 of the cycle) is to stabilize the P2 nanofiber morphology by crosslinking activated due to the existence of PA, i.e. circumventing the melting of the base polymer at around $100^{\circ} \mathrm{C}$. The change vs stabilization of the morphologies of $\mathrm{P} 1$ and $\mathrm{P} 2$ type nanofibers will further be elaborated in the results section.

After curing, the nanocomposite samples were cut into a dog-bone shape with a $14 \mathrm{~cm}$ length and $1 \mathrm{~cm}$ width. The specimen thickness measured around $0.5 \mathrm{~mm}$, and the specimen mass weighted about $1.08 \mathrm{~g}$. The rectangular CFRC specimens were cut out from the panels in size of $2.5 \mathrm{~cm} \times 25 \mathrm{~cm}$ using waterjet. To avoid sliding of composite specimens in between the jaws of the grips, $2.5 \mathrm{~cm} \times 5 \mathrm{~cm}$ aluminum tabs were glued to the both ends of the specimens.

All nanocomposites and composites were tested under uniaxial tension using Zwick/ Roell, Z100 Proline universal testing machine (UTM). The cross-head speed was set to $2 \mathrm{~mm} / \mathrm{min}$. The gauge length for nanocomposites was $10 \mathrm{~cm}$ and for composites were $15 \mathrm{~cm}$ according to ASTM 3039D3039M-14. 


\section{Results and Discussion}

\subsection{Compositional analysis}

Following our earlier work [5-7], glycidyl methacrylate (GMA) were successfully copolymerized with styrene. The copolymer was demonstrated to be compatible with epoxy resin because both the GMA and resin contain epoxy rings, which can create crosslinks. In the IR spectrum of the copolymer (Fig. 1), the epoxy group is identified with a peak around $800 \mathrm{~cm}^{-1}$. In addition, $\mathrm{C}=\mathrm{O}$ bond at 1750 $\mathrm{cm}^{-1}$ comes from GMA, which indicates the presence of this monomer in the structure, i.e. successful polymerization.

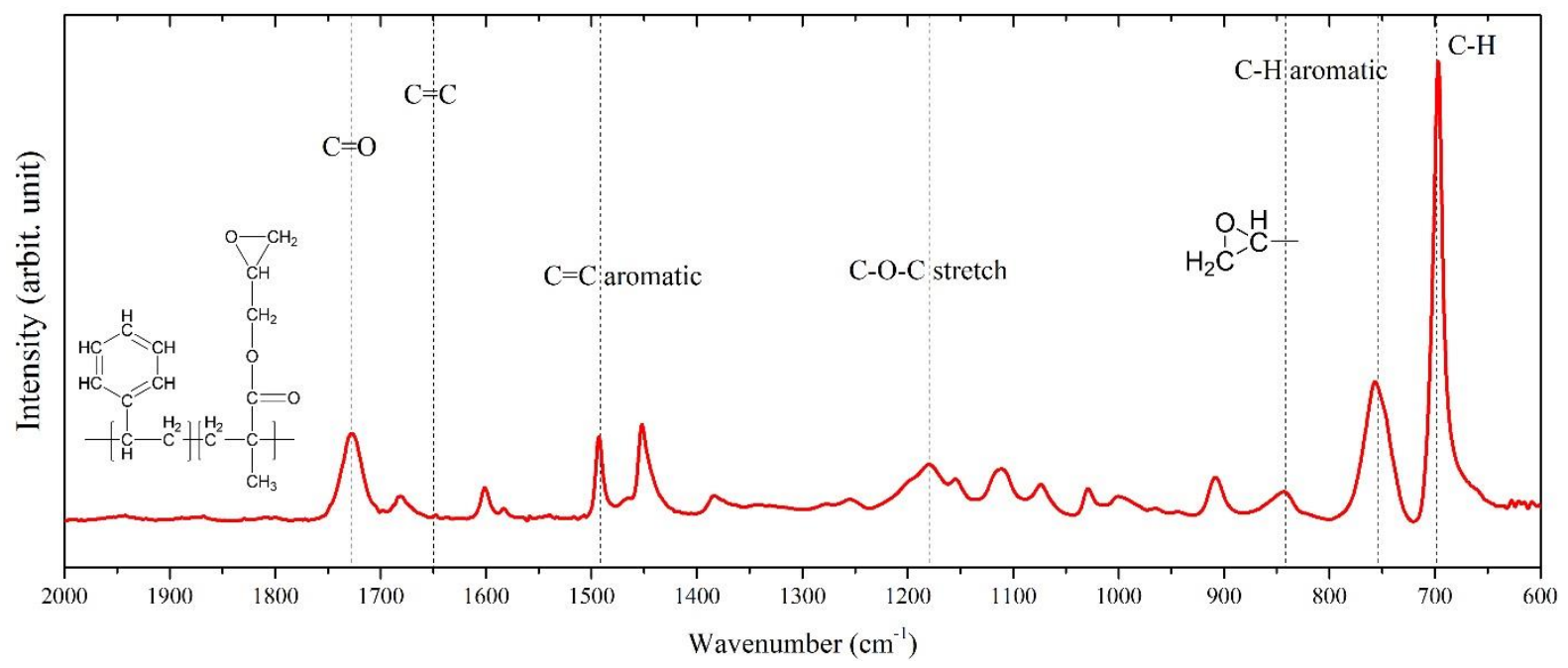

Figure 1: ATR FT-IR spectrum of $\mathrm{P}(\mathrm{St}-\mathrm{co}-\mathrm{GMA})$.

The peak around $1500 \mathrm{~cm}^{-1}$ belongs to the aromatic $\mathrm{C}=\mathrm{C}$ which comes from styrene. The lack of a $\mathrm{C}=\mathrm{C}$ peak around 1650 confirmed the successful copolymerization. Lack of this peak shows that the $\mathrm{C}=\mathrm{C}$ double bonds in the monomers have broken and created single bonds along the copolymer backbone.

\subsection{Thermal analysis}

The TG curve of the copolymer P1 (Fig. 2 left) showed that the mass loss is negligible up to $250^{\circ} \mathrm{C}$. It means that the polymer does not decompose until this temperature. Thus, it can be heated with insignificant compositional changes in the polymer.
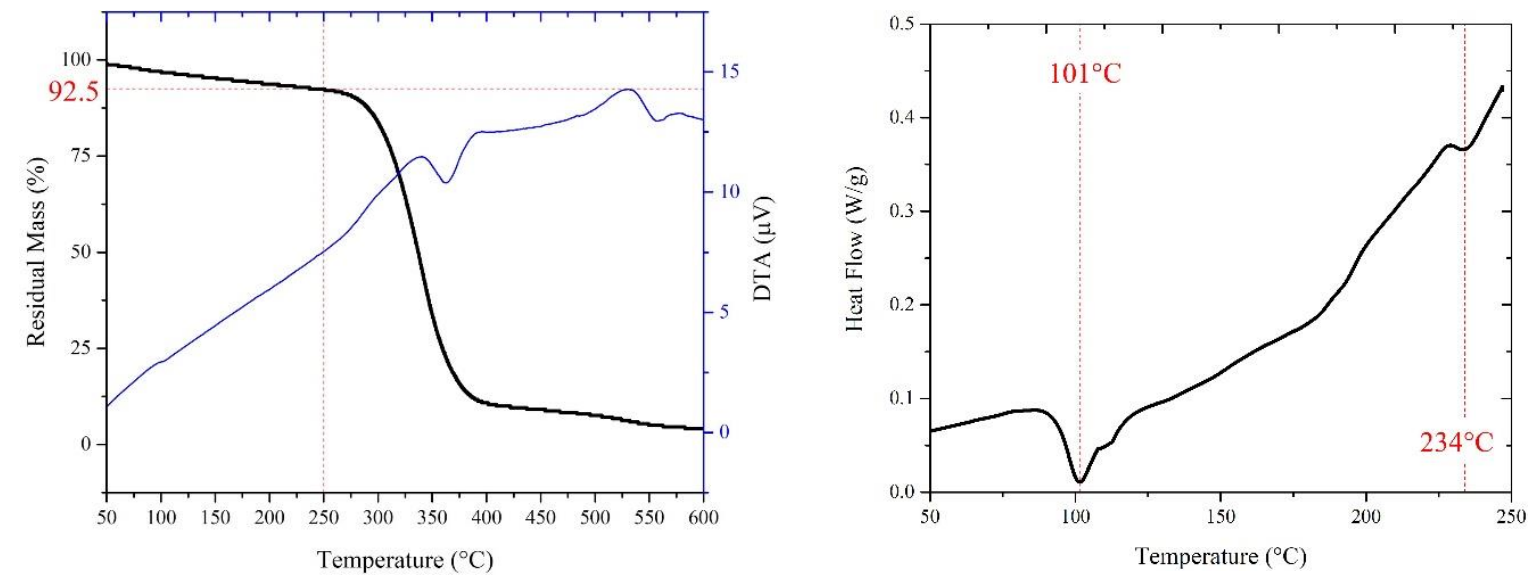

Figure 2: TG curve (left) and exo up DSC curve (right) from P(St-co-GMA).

The crucial changes to emphasize in this region are the transformation from rubbery to glassy state at the glass transition temperature $\left(\mathrm{T}_{\mathrm{g}}\right)$ and the complete melting temperature $\left(\mathrm{T}_{\mathrm{m}}\right)$ which are detected in 
the DSC curve (Fig. 2 right). $\mathrm{T}_{\mathrm{g}}$ is about $100^{\circ} \mathrm{C}$ and melting completes around $234^{\circ} \mathrm{C}$. These characteristic temperatures for $\mathrm{P} 1$ have been to consider along with the epoxy matrix curing cycle.

\subsection{Morphological analysis}

After P1 and P2 type nanofibers were prepared, they were heat treated at the $250^{\circ} \mathrm{C}$ which is above the melting temperature of the base polymer P1. The morphology of the nanofibers was investigated using SEM (Fig. 3) before and after the heat-treatment. In Fig. 3, the upper images showed the successful production of bead-free nanofibers of P1 and P2. The lower images of Fig. 3 showed the morphological changes on the nanofibers after heating up to $250^{\circ} \mathrm{C}$. After the heat-treatment, nanofibers of the base polymer P1 were found fully melted whereas the nanofibers of the crosslinkable mix, P2 were able to preserve their original fibrous morphology. These observations are consistent with our earlier work $[10,11]$ and prove the repeatability of our approach.
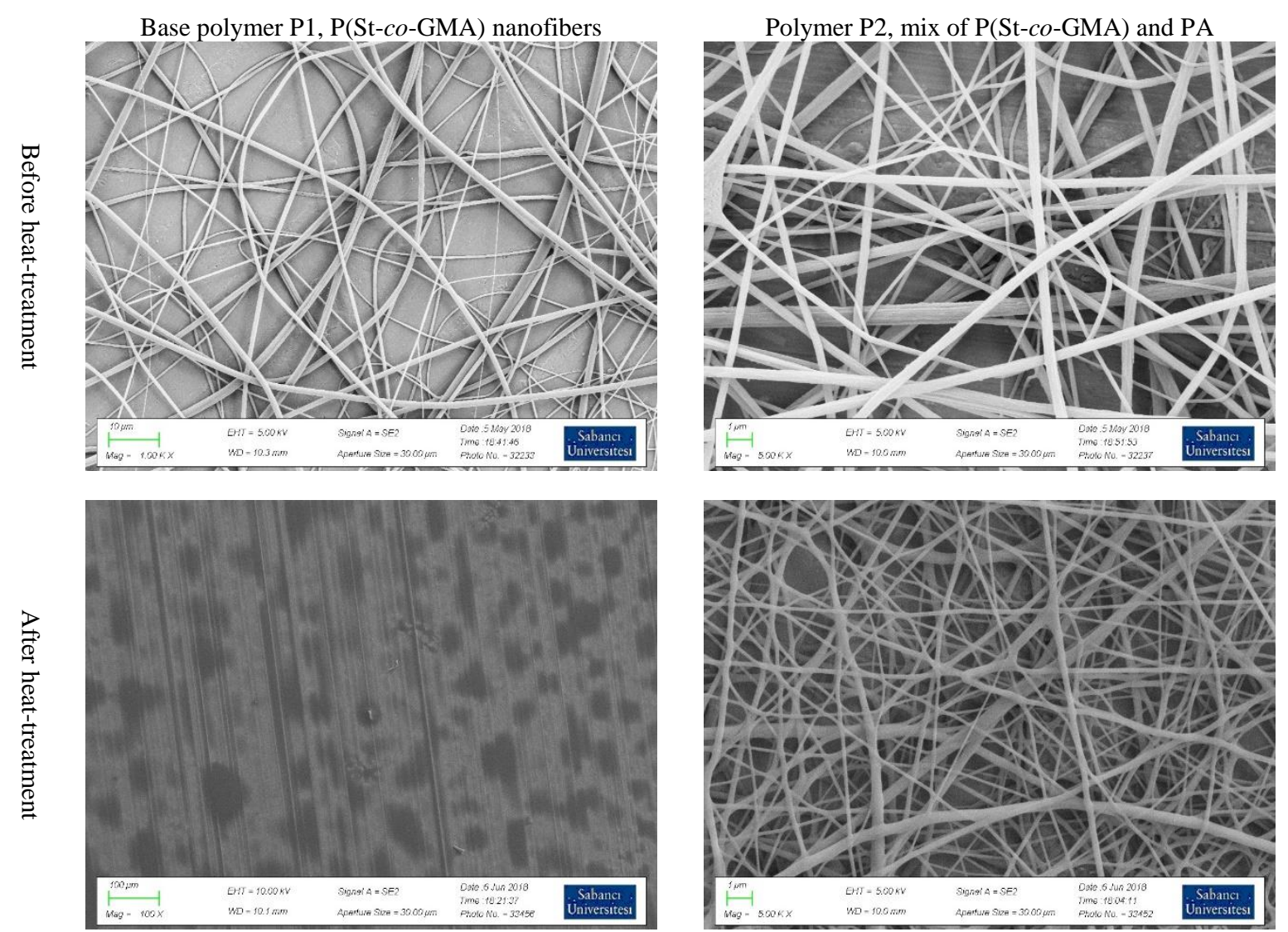

Figure 3: Nanofibers of the base polymer P1 and heat activated cross-linkable P2 the mix of polymer with PA before and after heat-treatment $\left(\mathrm{T}=250^{\circ} \mathrm{C}\right.$, beyond the melting temperature of $\left.\mathrm{P} 1\right)$.

As a continuation of the proposed dual-electrospinning scheme due to [10], simultaneous e-spin of P1 and P2 was applied forming intermingled nanofibers of the respective polymers on the same mat. The nanofibrous mat led to a special morpohology after the heat treatment as shown in Fig. 4 as a result of interaction of the P1 and P2 fibers. The resultant morpohology is called as the self-same nanofibrous mat as the base polymer P1 was fused over the P2 fibers which are made of the crosslinked derivation of the base P1 polymer. 

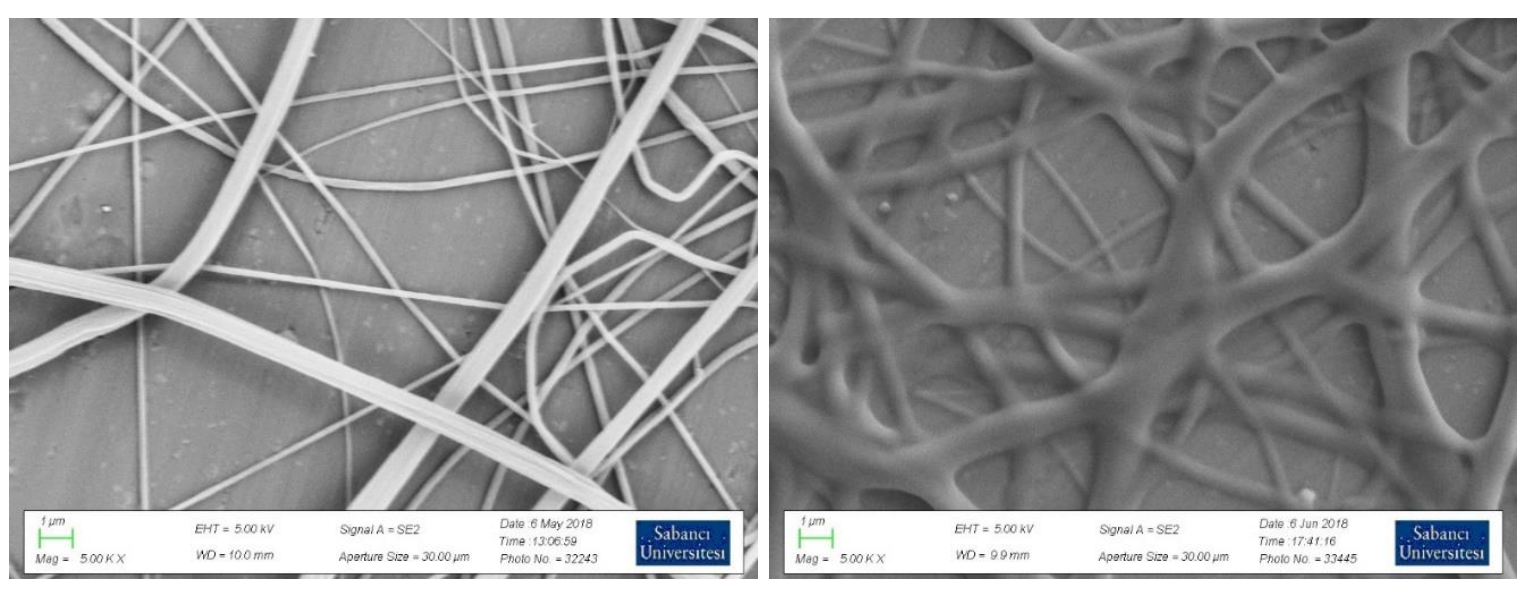

Figure 4: Dual-spun nanofibrous structure of P(St-co-GMA), P1 and the P2 (mix of P1 with PA), before (left) and after (right) heat-treatment.

The selfsame nanofiber changed morphologically upon heating. In fact, the melting nanofibers melted and covered the crosslinking fibers. Thus, the diameter of the fibers increased (Fig. 4). The strategy had worked well there. While some parts of the reinforcement melted to create a better interface with the matrix, the other part preserved the fibrous structure. Therefore, a selfsame nanofiber-reinforced composite was expected to be enhanced in mechanical behavior first due to the more compatible interface provided by the melting agent and, second, due to the fibrous structure provided by the crosslinking agent.

Samples of MCF loaded nanofibers were studied (Fig. 5). The upper left image in Fig. 5 demonstrated that the MCF loaded Pst-co-GMA fibers. By heating the sample upto 250C, P1 polymer nanofibers melted and the MCFs in the original mat were revealed (lower left image in Fig. 5). Nanofiber morphology was no longer available, and P1 nanofibers transformed into film loaded with MCFs. The upper and lower right micrographs of Fig. 5, on the other hand, show MCF loaded P2. The heat treatment did not change the structure of the crosslinking nanofibers. 

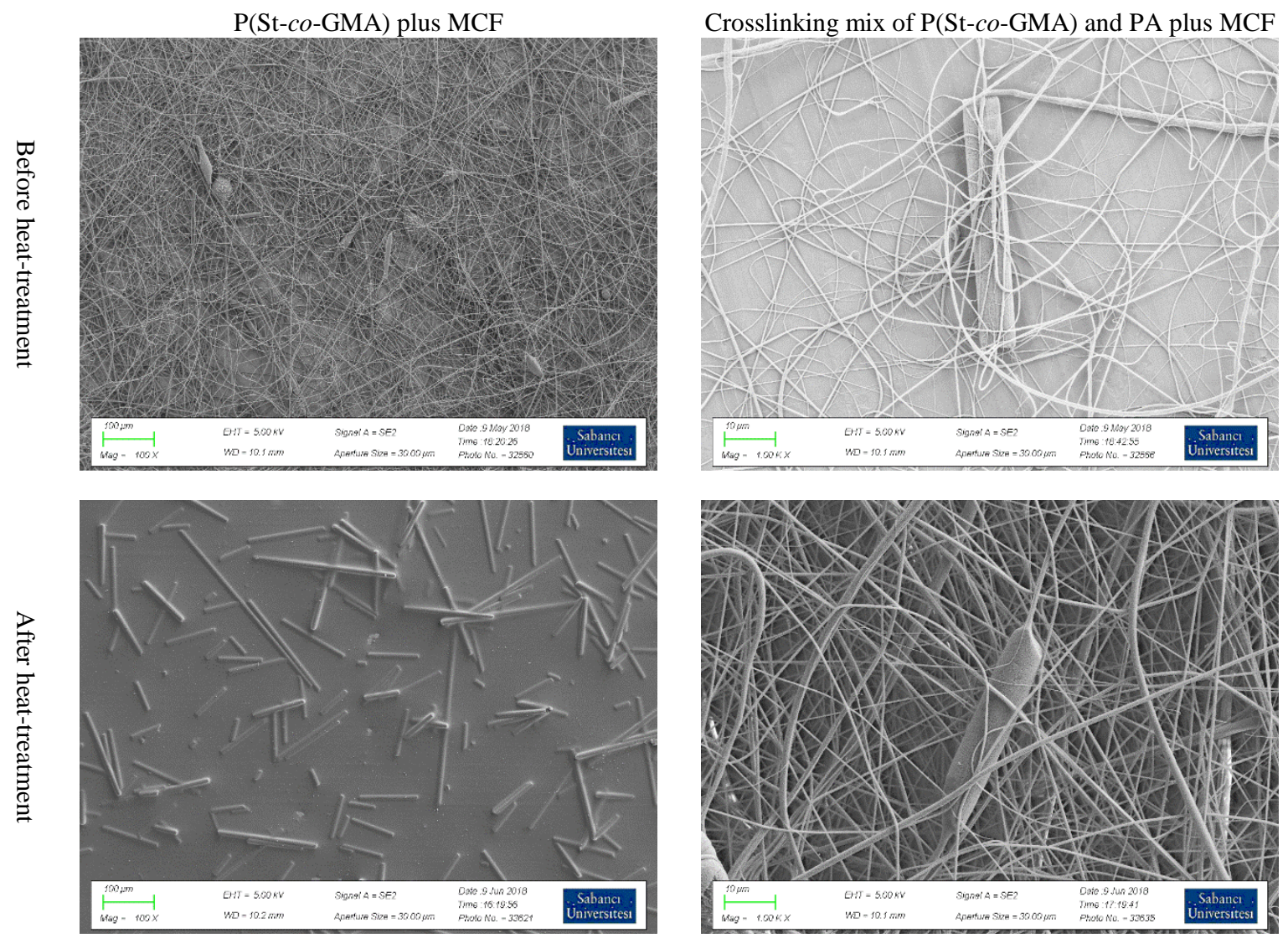

Figure 5: Morphology changes of nanofibrous structures, with MCF, P1/MCF (left), P2/MCF (right), before (up) and after (down) left treatment.

The production scheme for the self-same nanofibers adopted MCFs into the crosslinking mix. That is, the dual electrospinning of P2S suspension (Fig. 5) along with the P1 solution to achieve particle loaded self-same nanofibrous mats. To investigate the morphology changes in the case of the selfsame nanofibers, the samples were heat-treated as before and analyzed morphologically (Fig. 6). The images suggested that the fibrous structure was preserved after the heat-treatment.
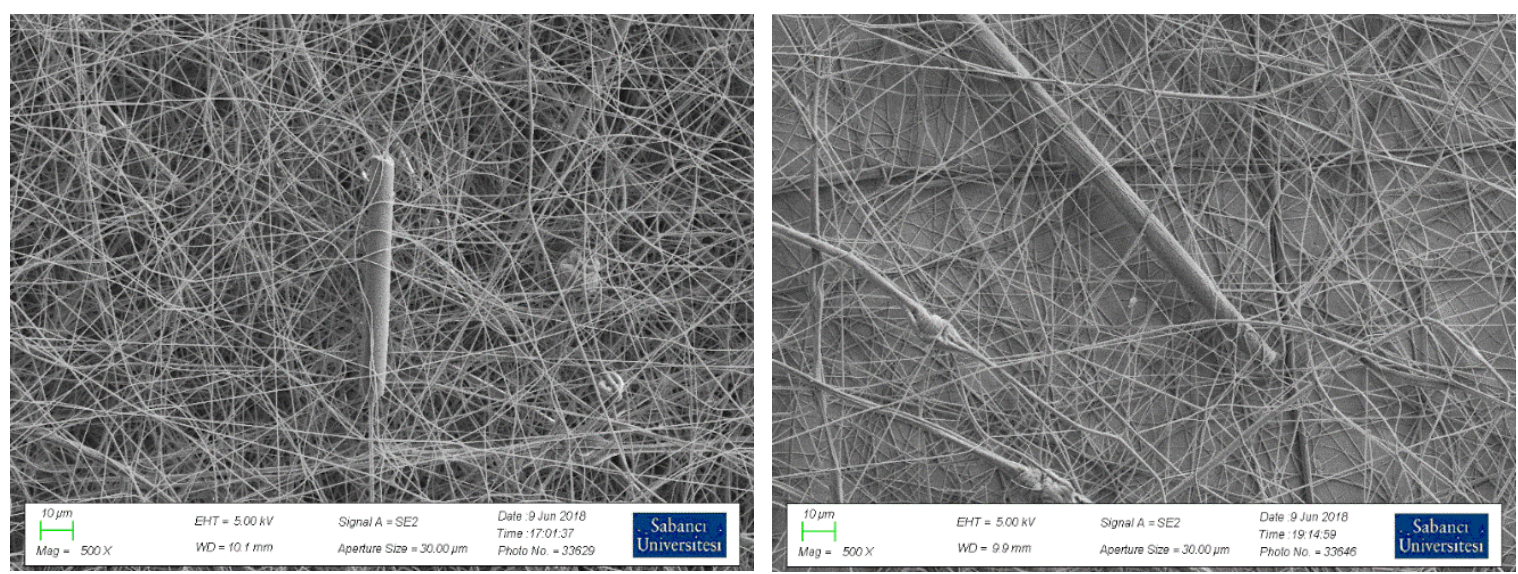

Figure 6: Morphology changes in the dual-spun polymer nanofibers P1 and P2S crosslinking mix of polymer and PA plus MCF before (left) and after (right) heat-treatment.

In SEM images, only the MCF's close to the surface were observed. To elaborate MCFs through the thickness of the nanofiber layer, visible light microscope (VLM) photomicrographs were taken and examined (Fig. 7). The MCF particles were distributed homogenously throughout the mat. The 
images also revealed the fact that, when the fibers were heated, the base polymer P1 lost its fibrous structure whereas the crosslinking sample preserved its fibrous morphology.

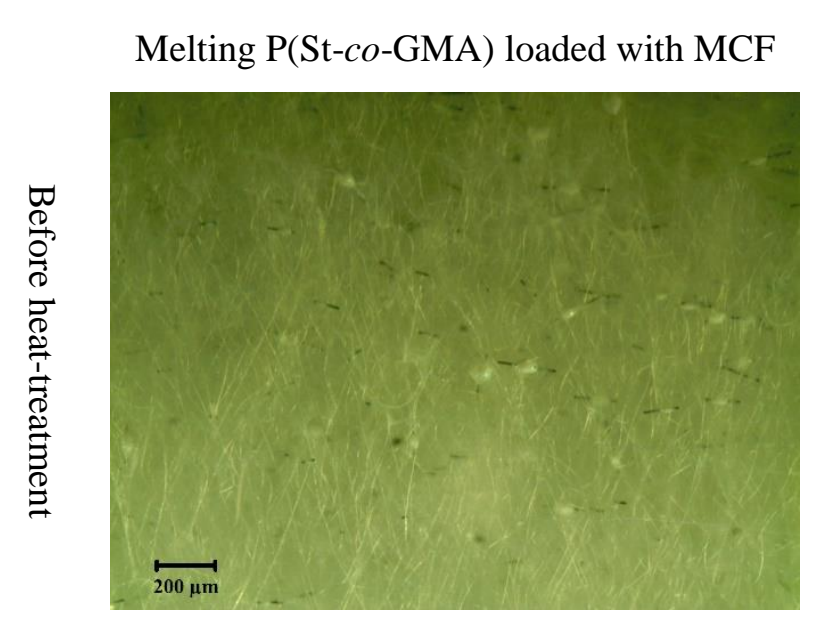

Crosslinking mix of P(St-co-GMA) and PA
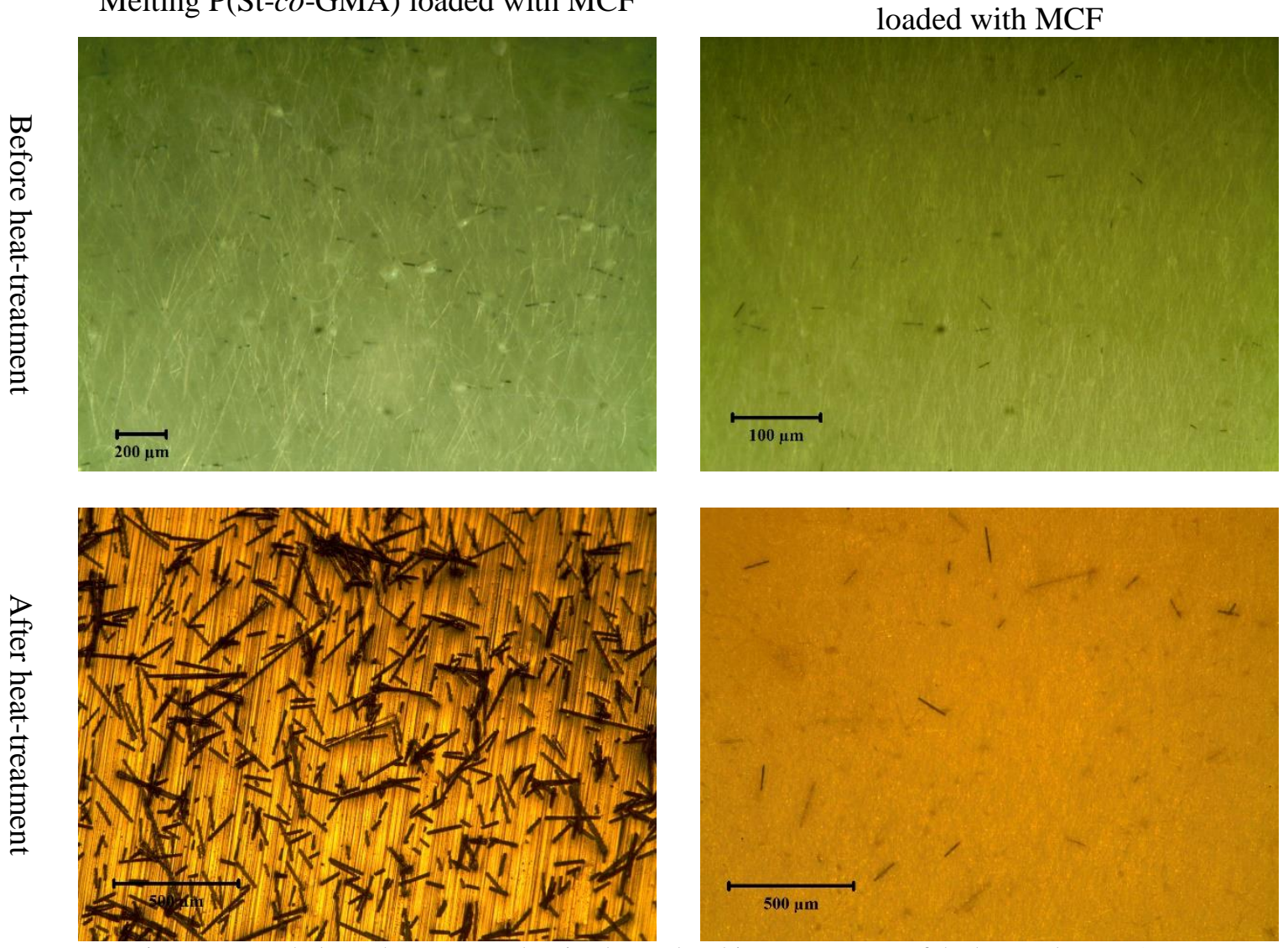

Figure 7: Morphology changes upon heating beyond melting temperature of the base polymer P1.

The dual-espun sample was also investigated via VLM (Fig. 8). The fibrous structure of the nanofibers was preserved despite the heat-treatment
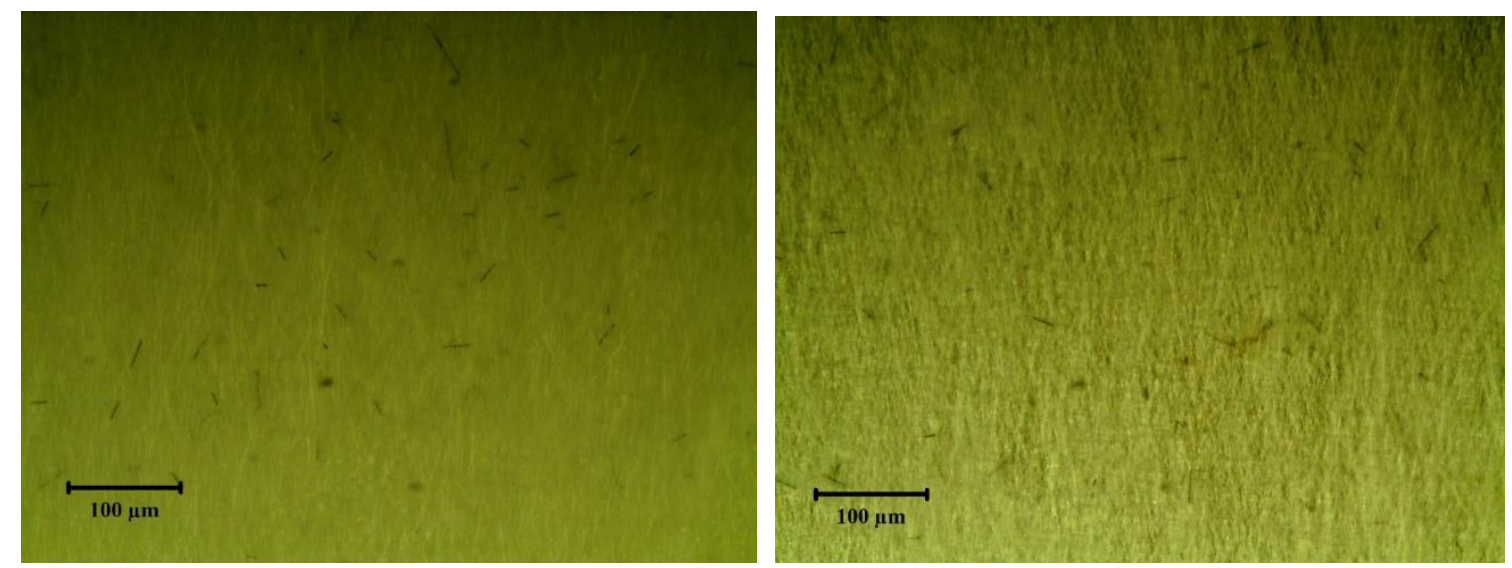

Figure 8: Morphology changes of the MCF loaded dual-espun nanofibers (P1 and P2S) due to heating, before (left) and after (right)

\subsection{MCF content determination}

Only $1.5 \mathrm{wt} . \%$ particle content was measured for MCF in the dual-espun, i.e. self-same nanofibrous mat (Fig. 9). The transfer rate was measured to be $3 \mathrm{wt} . \%$ in the case of crosslinking polymer alone. 


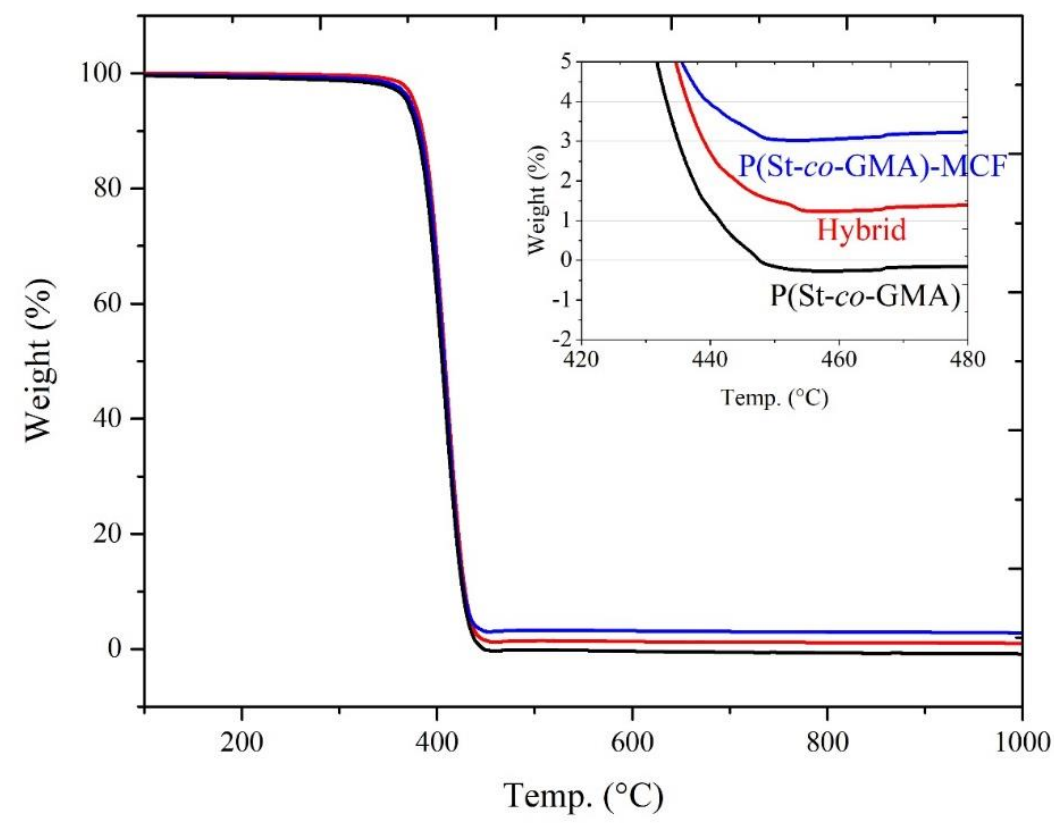

Figure 9: Thermogravimetry under nitrogen medium for, nanofibers from P1- P(St-co-GMA), P2S- P(St-co-GMA)-MCF loaded, and their hybrid (dual espun or self-same).

\subsection{Effects of MCF loaded self-same nanofibers in mechanical properties of composites}

Nanocomposite specimens prepared by epoxy resin film and self-same nanofiber mats with and without MCF loading were tested under tension. Data available to date is sparse, in particular on the strength and more testing is underway to be conclusive. However, the elastic modulus of the MCF loaded self-same nanofiber reinforced nanocomposites was found higher about $9 \%$ compared to the tests on specimens without the MCFs (Table 1 and Fig. 10).

Table 1: Mechanical properties of nanocomposites reinforced by selfsame nanofibers and MCF-loaded selfsame nanofibers.

\begin{tabular}{|l|l|l|}
\hline Specimen reinforcement & Elastic Modulus (MPa) & Change (\%) \\
\hline Selfsame & $523 \pm 30$ & - \\
\hline Selfsame-MCF & $569 \pm 29$ & 8.79 \\
\hline
\end{tabular}
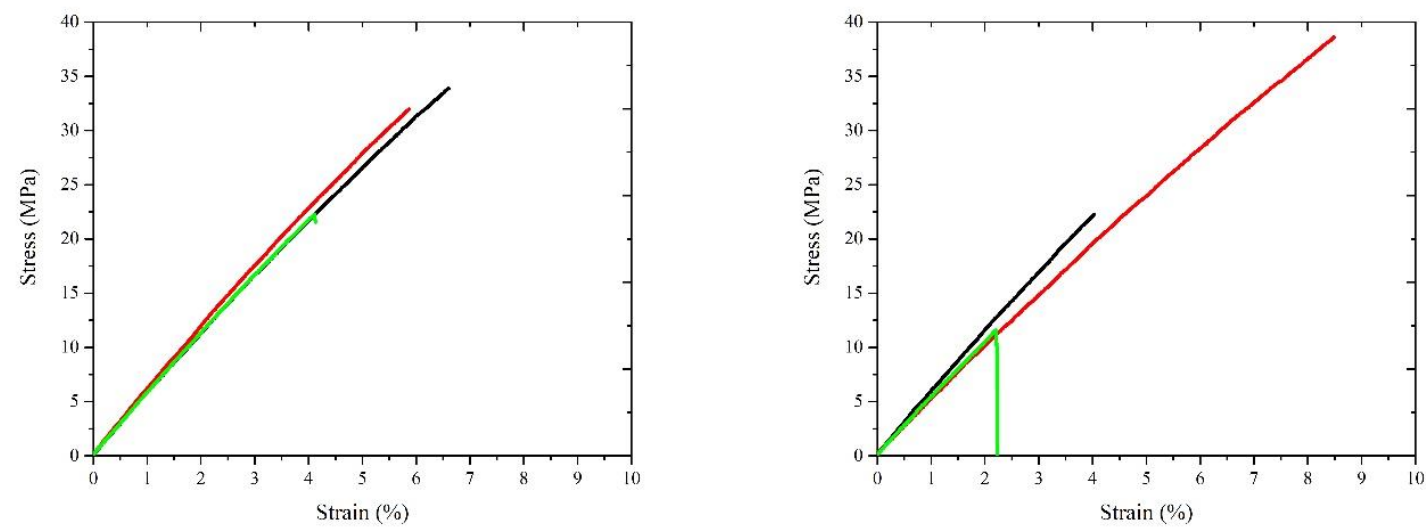

Figure 10: Tensile test results for nanocomposites reinforced with the MCF-loaded self-same nanofibers (left) and self-same nanofibers without MCF (right). 
Cross-ply CFRC specimens were interleaved by MCF-loaded selfsame nanofibers. The interlayers increased the stiffness and ultimate strength of the composites by about $4 \%$ and $9 \%$, respectively (Table 2).

Table 2: Mechanical properties of standard CFRC and CFRC with the interlayers of MCF-loaded selfsame P(St-co-GMA) nanofibers.

\begin{tabular}{|l|l|l|l|l|}
\hline $\begin{array}{l}\text { CFRC specimen } \\
\text { layup }\end{array}$ & $\begin{array}{l}\text { Elastic Modulus } \\
(\mathrm{GPa})\end{array}$ & $\begin{array}{l}\text { Change in Elastic } \\
\text { Modulus (\%) }\end{array}$ & $\begin{array}{l}\text { Ultimate strength } \\
(\mathrm{MPa})(\text { Change } \%)\end{array}$ & $\begin{array}{l}\text { Change in Elastic } \\
\text { Modulus }(\%)\end{array}$ \\
\hline$(0 / 90)_{\mathrm{s}}$ & $58.5 \pm 6.51$ & - & $723 \pm 48.4$ & - \\
\hline $\begin{array}{l}(0 / \mathrm{I} / 90 / \mathrm{I} / 90 / \mathrm{I} / 0) \\
\begin{array}{l}\mathrm{I}: \text { Self-same/MCF } \\
\text { nanofibers }\end{array}\end{array}$ & $60.8 \pm 4.50$ & 3.91 & $787 \pm 54$ & 8.85 \\
\hline
\end{tabular}

The results suggest that the interlayered composites resisted more against the matrix crack driven failure (Fig. 11). This is attributed to both higher ultimate strength values and the progressive strength pick-up marks of on the stress-strain curves of the interlayered CFRC's (Fig. 11, right). The curves suggest in the interlayered CFRC's, the cracks were suppressed by the interlayers right at the interface, then they deflected and forced to trace the boundaries of the laminae which already were covered by the nanofiber interlayers. The failure mode, thus, changed from matrix failure dominated mode in the standard CFRC case to much more of delamination and ply splitting dominated in the the interlayered CFRC, but with increased strength (compare the insets of Fig. 11).
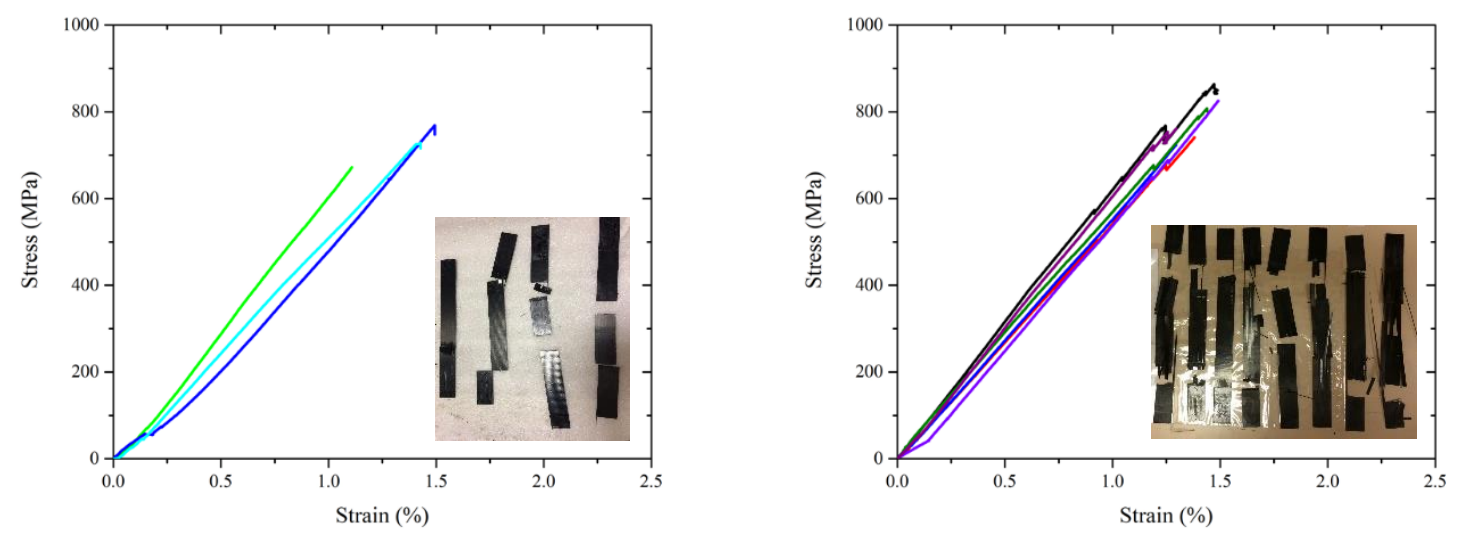

Figure 11: Tensile test results and failed specimens of neat CFRC (left) and CFRC interlayered with the selfsame P(St-coGMA) nanofibers impregnated with MCF (right).

\subsection{Discussion on Toughening Mechanism via Failure Surfaces}

The toughening mechanism by the self-same nanofibrous interlayers consisted of two major mechanisms: in the constituent (micro) and laminate (macro) levels (Figure 12). As depicted in the fractured specimen micrographs (Figure 12) the ultimate failure of un-reinforced laminates was due to fiber failure occurring at the middle of the test specimens whereas for nanofiber/MCF integrated specimens the failure was rather complex with apparent marks of $\left(90^{\circ}\right)$ block failure, ply splitting and delaminated (0/90) ply interfaces. Failure of a cross-ply laminate under tension typically initiates with transverse/matrix cracking due to weakness of $90^{\circ}$ plies in the loading direction [12]. These microcracks typically get multiplied at the random locations in the gauge region and subsequently lead major failure modes like delamination and ply-splitting depending on the crack propagation mechanisms. In order to understand the role of nanofibrous interlayers, two adjacent parts of the fracture surfaces are investigated: i) corresponding to top part of a failed $\left(90^{\circ}\right)$ block (in contact with the bottom of the subsequent $0^{\circ}$ ply) and ii) the bottom of a delaminated $0^{\circ}$ ply (delaminated from the first surface). Figure 12A and $12 \mathrm{C}$ exemplifies two major failure modes such as interlaminar failure and ply-splitting. 

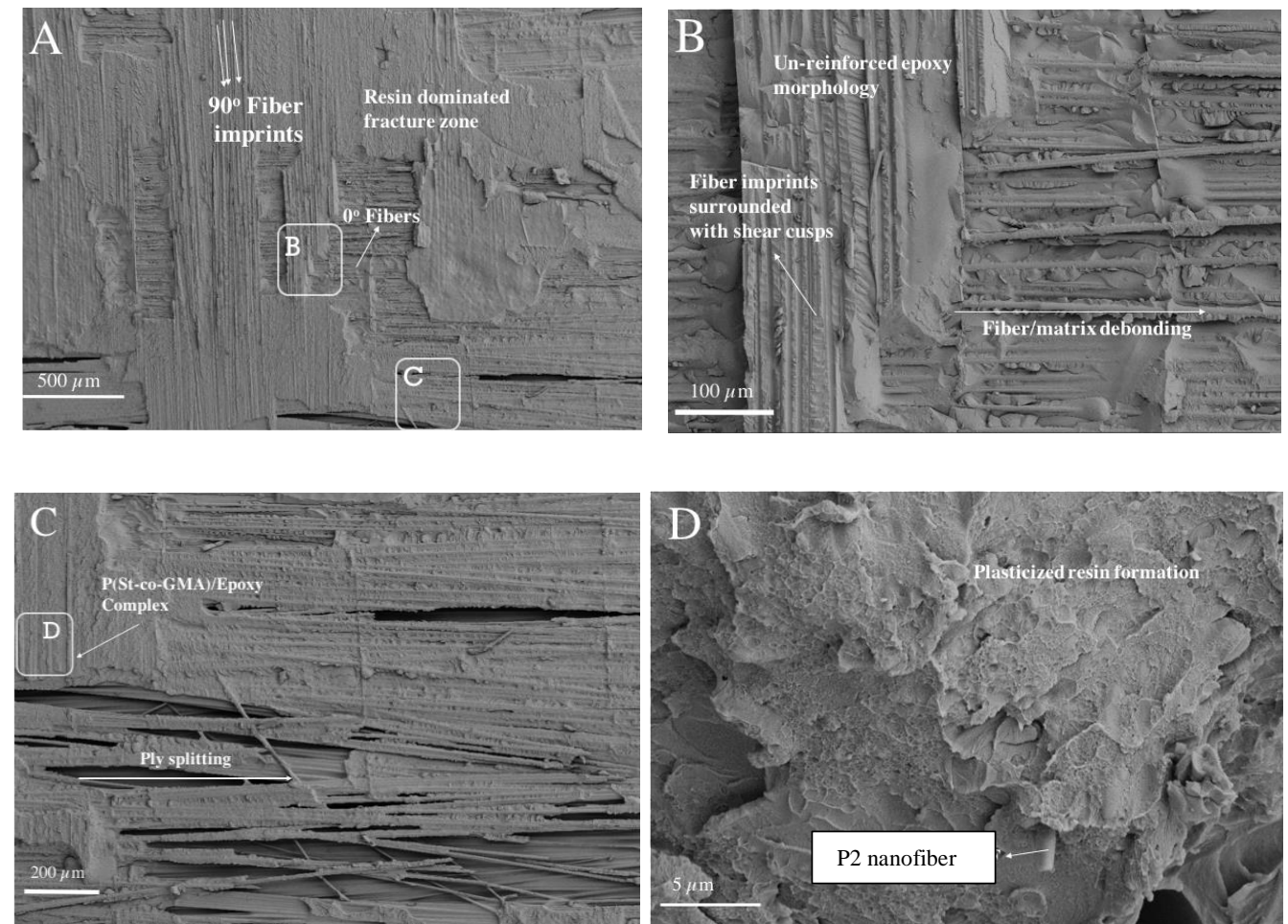

$-90^{0}$ ply surfaces
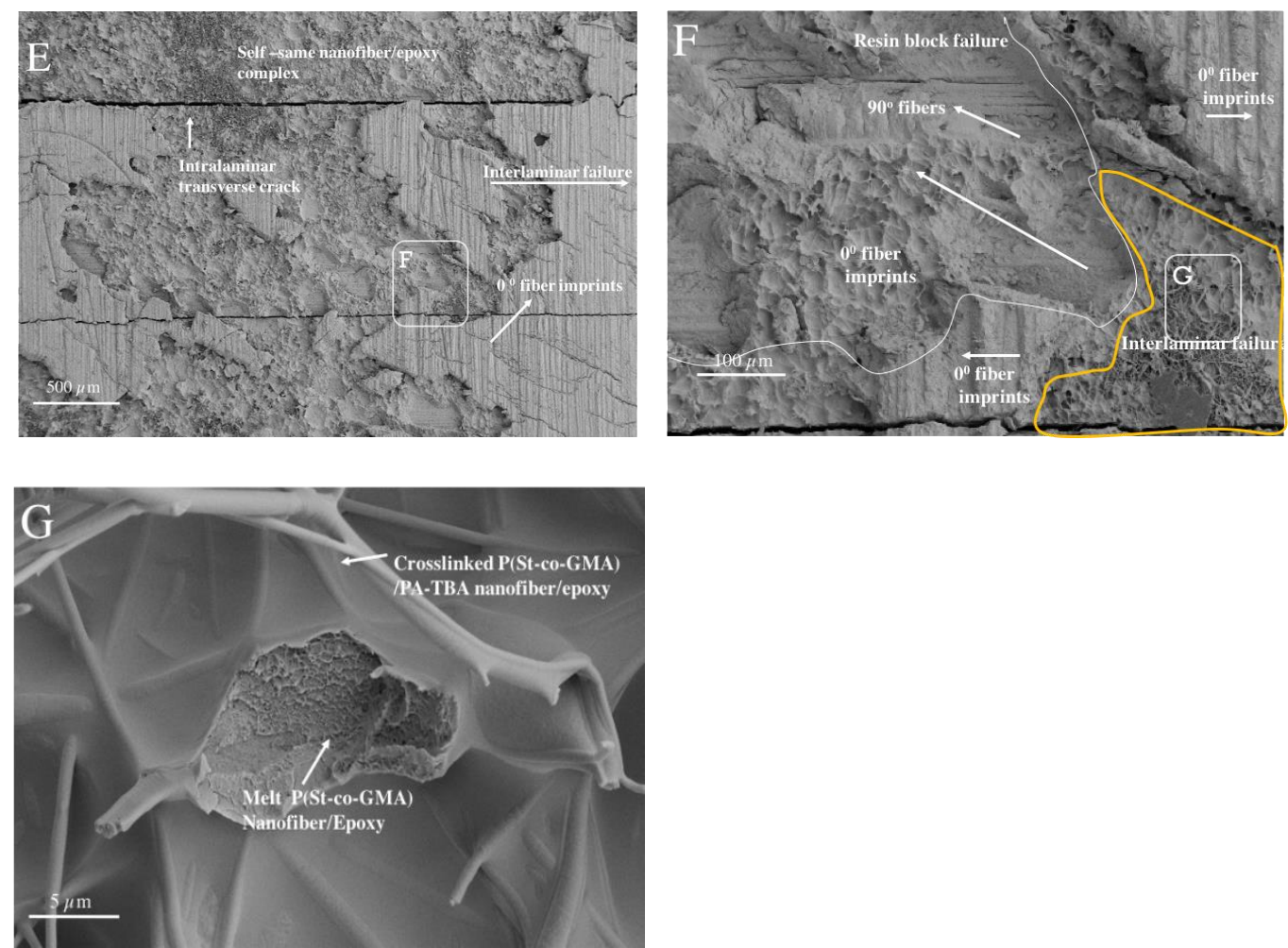

Figure 12: Tensile test results and failed specimens of neat CFRC (left) and CFRC interlayered with the selfsame P(St-co-GMA) nanofibers impregnated with MCF (right). 
As depicted in Figure 12A, the fracture surface consisted of large resin blocks with fiber imprints and local appearance of $0^{\circ}$ fibers underneath which suggests that an interlaminar crack locally deflected towards $0^{\circ}$ plies has caused the final failure. $90^{\circ}$ fiber imprints on the resin surfaces (Figure1B) suggests that the delamination due to mode I crack propagation has occurred. These fiber imprints were more distinguishable when appeared on un-reinforced resin failure surfaces (figure12B) and fuzzy when appeared on P(St-co-GMA)(melt)/epoxy complex (figure12D). There is also an exposed cross-linked P(St-co-GMA)/TBA-PA fiber in Figure 12D. This non-fibrous dominant observation suggests the fact that a part of melt P(St-co-GMA) has interacted with epoxy resin while separating itself from dual-electrospun nanofiber mix and plays a significant role on the specimen fracture [5] The matrix structure in Figure 12D shows that this interaction gives a more plasticized resin microstructure that can be more effective against crack propagation. The progressive failure of interlayered specimens is more apparent when $90^{\circ}$ ply surfaces are investigated. Figure $12 \mathrm{E}$ is an informative micrograph where intralaminar and interlaminar crack formation can be seen as well as the altered resin morphology when the self-same nanofibers were integrated (figure 12G). Similar to figure 12A, figure 12E also shows resin block formation with fiber imprints on their surfaces however the localized appearance of $0^{\circ}$ fibers in ply surfaces has been replaced by the self-same nanofiber/epoxy complex which is partly able to crosslink [13] with epoxy resin and to modify the surrounding resin morphology [10] (figure 12G). Crack deflection mechanism associated with the self-same/nanofibers is shown in Figure $12 \mathrm{~F}$ where interlaminar failure is locally deflected towards $90^{\circ}$ plies causing resin fracture.

When two fracture surfaces are compared following conclusions are suggested:

- $\quad$ Self-same nanofibrous interlayers not only act as "interlayer" (preserved fibrous parts, P2), but also as a resin modifier (meltin part P1) at multiple scales (Figure 12D and Figure 12G)

Self-same nanofibrous interlayers plays an effective role in the transverse cracking of $90^{\circ}$ plies and form obstacles for them to grow/propagate and multiply. More severe fracture modes such as ply splitting and delaminations occur at higher stresses, leading to strength improvement. Local load-drops in stress-strain curves before ultimate failure also supports that interaction.

- $\quad$ Presence of the self-same nanofibers produces a rather complicated fracture surfaces with apparent crack deflection regions that might contribute to the strength of laminates.

\section{Conclusion}

For epoxy matrix nanocomposites and composites, an epoxy-compatible polymer was synthesized by modification of polystyrene with additional functional sites - P(St-co-GMA) [5-7]. In this copolymer, a potential disadvantage was detected as a change in the fiber morphology during the composite cure, and it was tackled by implementing a selfsame strategy [10]. Moreover, MCF particles were added to the reinforcement system to further enhance the properties of the nanocomposites and composites. Morphological analysis revealed that the crosslinking nanofibers preserved their structure up to $250^{\circ} \mathrm{C}$. The self-same nanofiber approach was demonstrated successfully as the melting of the base polymer $\mathrm{P}(\mathrm{St}-\mathrm{co}-\mathrm{GMA})$ and covering of the crosslinking $\mathrm{P}(\mathrm{St}-\mathrm{co}$-GMA)/PA. MCF particles was loaded into the mix of $\mathrm{P}(\mathrm{St}-\mathrm{co}$-GMA) and PA. Then, the particles were transferred in that carrying medium using electrospinning technique. The particles were distributed homogenously as carried the nanofibers. The loaded MCF content was measured to be $3 \mathrm{wt} . \%$ for crosslinking P(St-co-GMA)/PA nanofibers alone and $1.5 \mathrm{wt} . \%$ for the self-same nanofiber mat by dual-electrospinning followed by a heat treatment. Nanocomposites were successfully obtained by impregnation of the self-same nanofiber reinforcement by epoxy resin film. The presence of MCF in this structure led to an $9 \%$ increase in the elastic modulus. CFRC's were also enhanced by using the self-same MCF loaded nanofiber interlayers. The implementation of this interlayer resulted in about $9 \%$ increase in the ultimate tensile strength. The research demonstrated the potential of MCF and nanofiber 
reinforcement as an effective reinforcement for nanocomposites and useful interlayer for fiber reinforced composite. The results call for further research in fiber-particle combinations as well as particle loading optimizations.

\section{References}

[1] G. Wang, D. Yu, A. D. Kelkar, and L. Zhang, "Electrospun nanofiber: Emerging reinforcing filler in polymer matrix composite materials," Progress in Polymer Science, 2017.

[2] B. D. Agarwal, L. J. Broutman, and K. Chandrashekhara, Analysis and performance of fiber composites: John Wiley \& Sons, 2017.

[3] A. Zucchelli, M. L. Focarete, C. Gualandi, and S. Ramakrishna, "Electrospun nanofibers for enhancing structural performance of composite materials," Polymers for Advanced Technologies, vol. 22, pp. 339-349, 2011.

[4] K. Bilge and M. Papila, "Ch. 10 - Interlayer toughening mechanisms of composite materials A2 - Qin, Qinghua," in Toughening Mechanisms in Composite Materials, J. Ye, Ed., ed: Woodhead Publishing, 2015, pp. 263-294.

[5] K. Bilge, E. Ozden-Yenigun, E. Simsek, Y. Menceloglu, and M. Papila, "Structural composites hybridized with epoxy compatible polymer/MWCNT nanofibrous interlayers," Composites Science and Technology, vol. 72, pp. 1639-1645, 2012.

[6] E. Ozden, A. R. Atilgan, K. Bilge, Y. Menceloglu, C. Atılgan, and M. Papila, "Designed-in Molecular Interactions Lead to Superior Thermo-mechanical Properties in Nanocomposites," MRS Online Proceedings Library Archive, vol. 1304, 2011.

[7] E. Ozden, Y. Z. Menceloglu, and M. Papila, "Engineering chemistry of electrospun nanofibers and interfaces in nanocomposites for superior mechanical properties," ACS applied materials \& interfaces, vol. 2, pp. 1788-1793, 2010.

[8] K. Bilge, S. Venkataraman, Y. Menceloglu, and M. Papila, "Global and local nanofibrous interlayer toughened composites for higher in-plane strength," Composites Part A: Applied Science and Manufacturing, vol. 58, pp. 73-76, 2014.

[9] K. Bilge, "Multi-scale nature of composite materials: Three case studies," 2012.

[10] K. Bilge, A. Ürkmez, E. Şimşek, and M. Papila, "Stabilized electrospinning of heat stimuli/in situ crosslinkable nanofibers and their self-same nanocomposites," Journal of Applied Polymer Science, vol. 133, 2016.

[11] Papila, M., Bilge, K., Simsek, E., Urkmez, A., Menceloglu, Y., Ozden-Yenigun, E., "Stable Electrospinning Composition for Stable Nano/Submicrostructure Production and Preparation Method Thereof," WO2016/190826, 2016.

[12] Bilge, K., Yilmaz, B., \& Papila, M. (2016). Sound-tracking of failure events in cross-ply composite laminates under tension. Composite Structures, 153, 421-427.

[13] Bilge, K., Yorulmaz, Y., Javanshour, F., Ürkmez, A., Yılmaz, B., Şimşek, E., \& Papila, M. (2017). Synergistic role of in-situ crosslinkable electrospun nanofiber/epoxy nanocomposite interlayers for superior laminated composites. Composites Science and Technology, 151, 310-316. 